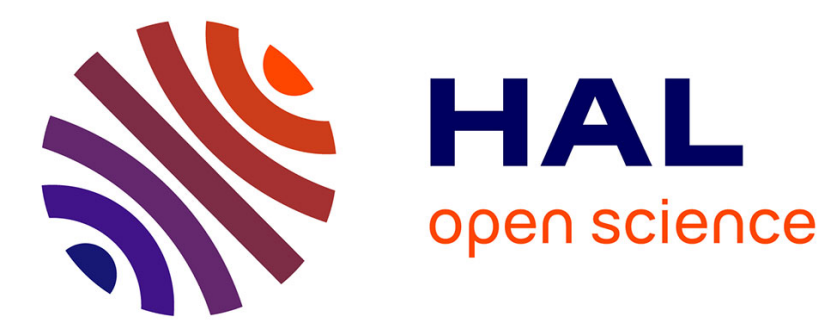

\title{
Relationships between declarative pointing and theory of mind abilities in 3-to 4-year-olds
}

Hélène Cochet, Marianne Jover, Cécile Rizzo, Jacques Vauclair

\section{To cite this version:}

Hélène Cochet, Marianne Jover, Cécile Rizzo, Jacques Vauclair. Relationships between declarative pointing and theory of mind abilities in 3-to 4-year-olds. European Journal of Developmental Psychology, 2017, 14 (3), pp.324-336. 10.1080/17405629.2016.1205975 . halshs-01464551

\section{HAL Id: halshs-01464551 \\ https://shs.hal.science/halshs-01464551}

Submitted on 11 Jul 2017

HAL is a multi-disciplinary open access archive for the deposit and dissemination of scientific research documents, whether they are published or not. The documents may come from teaching and research institutions in France or abroad, or from public or private research centers.
L'archive ouverte pluridisciplinaire HAL, est destinée au dépôt et à la diffusion de documents scientifiques de niveau recherche, publiés ou non, émanant des établissements d'enseignement et de recherche français ou étrangers, des laboratoires publics ou privés. 


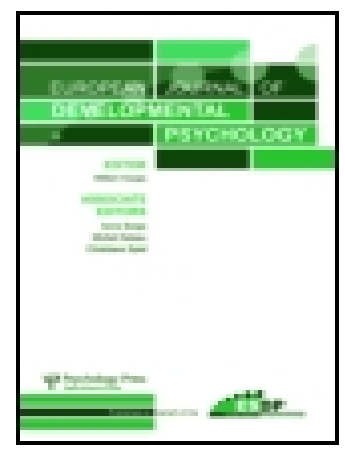

European Journal of Developmental Psychology

\section{Relationships between declarative pointing and theory of mind abilities in 3- to 4-year-olds}

\section{Hélène Cochet, Marianne Jover, Cécile Rizzo \& Jacques Vauclair}

To cite this article: Hélène Cochet, Marianne Jover, Cécile Rizzo \& Jacques Vauclair (2016): Relationships between declarative pointing and theory of mind abilities in 3- to 4-year-olds, European Journal of Developmental Psychology, DOI: 10.1080/17405629.2016.1205975

To link to this article: http://dx.doi.org/10.1080/17405629.2016.1205975

央 Published online: 06 Jul 2016.

Submit your article to this journal $[\pi$

View related articles $\sqsubset$

View Crossmark data $₫$ 


\title{
Relationships between declarative pointing and theory of mind abilities in 3- to 4-year-olds
}

\author{
Hélène Cochet $^{\mathrm{a}}$, Marianne Jover ${ }^{\mathrm{b}}$, Cécile Rizzo ${ }^{\mathrm{b}}$ and Jacques Vauclair ${ }^{\mathrm{b}}$ \\ aLaboratory CLLE LTC, UMR 5263, Department of Psychology, University Toulouse Jean Jaurès, \\ Toulouse Cedex 9, France; 'bepartment of Psychology, Aix Marseille Université, PSYCLE EA 3273, \\ Aix en Provence, France
}

\begin{abstract}
The current study explored the relationships between declarative pointing and theory of mind abilities in 30 children between 3 and 4 years of age. Measures used to examine theory of mind (ToM) included a parental questionnaire and the Scaling of Theory of Mind Tasks. Results showed a dissociation between expressive and informative pointing, which have been regarded as two subcategories of the declarative function. ToM abilities were significantly related to the production of informative pointing, but not to the production of expressive pointing. This distinction might be explained by special features associated with informative pointing, such as early signs of cooperation abilities. Our results might have key implications for psychologists, as they may help improve evaluation and intervention programs for the development of social skills in preschoolers.
\end{abstract}

ARTICLE HISTORY Received 2 December 2015; Accepted 21 June 2016

KEYWORDS Declarative pointing; informative pointing; expressive pointing; theory-of-mind abilities

\section{Introduction}

Infants are able to establish joint attentional frames with the adult from 9 months of age, through gaze, facial expressions and vocalizations (e.g. Mundy \& Newell, 2007). The intentional use of gestures around the end of the first year allow them to maintain and enrich these interactions, thus playing an important role in the development of later social and cognitive abilities, including language acquisition and theory of mind (ToM) skills (e.g. Camaioni, Perucchini, Bellagamba, \& Colonnesi, 2004; Charman et al., 2001; Colonnesi, Stams, Koster, \& Noom, 2010). The production of communicative gestures in the course of development has been extensively studied, and has led to a thorough description of children's gestures, both in terms of form and function (e.g. Behne, Carpenter, \& Tomasello, 
2014; Cochet \& Vauclair, 2010a; Stefanini, Bello, Iverson, Caselli, \& Volterra, 2009). Given the diversity of this gestural repertoire, researchers have sought to determine whether some gestures are more closely related than others to the development of socio-cognitive abilities (e.g. Liszkowski, 2008).

Pointing has been regarded as a privileged precursor to these abilities, especially when the imperative and declarative functions of pointing are considered separately: children use imperative pointing to request a specific object (or a specific action) from the adult and declarative pointing to share with the adult some exciting or useful information about a referent. The production of declarative pointing was shown to be significantly related to intention understanding in 12-15 month-old infants (Camaioni et al., 2004), to ToM abilities in 3-year-old children (Kristen, Sodian, Thoermer, \& Perst, 2011), and to language skills throughout development (e.g. Cochet, Jover, \& Vauclair, 2011; Colonnesi et al., 2010). Young infants' understanding of adults' imperative pointing was also found to predict later ToM abilities, but this relationship, contrary to the one observed for the production of imperative pointing, was argued to reflect a form of cooperative engagement necessary for the task used by the authors (Colonnesi, Rieffe, Koops, \& Perucchini, 2008).

Moreover, impairment in the production of declarative pointing is considered as a potential sign of autistic disorder in toddlers (e.g. Camaioni, Perucchini, Muratori, Parrini, \& Cesari, 2003), in addition to (and possibly in relation to) the well-documented ToM impairments in individuals with autism (see Yirmiya, Erel, Shaked, \& Solomonica-Levi, 1998). Children with Williams syndrome also show atypical development of triadic joint attention and ToM abilities (e.g. Mervis \& Klein-Tasman, 2000; Porter, Coltheart, \& Langdon, 2008). The emergence of referential pointing is for example usually delayed several months after the onset of language (see Mervis \& John, 2010), with evidence suggesting difficulty with the declarative function but not with the imperative function (Asada \& Itakura, 2012).

In addition, in typically developing children, ToM abilities have been reported to be contingent on children's language level, for example in false-belief understanding (Milligan, Astington, \& Dack, 2007), but the use of nonverbal tasks (requiring for example the re-enactment of others' intended acts after seeing failed attempts to perform these acts: see Meltzoff, 1995), has shown that preverbal infants are capable of early comprehension of others' intentions and desires (e.g. Knudsen \& Liszkowski, 2012; Onishi \& Baillargeon, 2005; Repacholi \& Gopnik, 1997; Southgate, Senju, \& Csibra, 2007). Children's experience of declarative communicative situations, experience that first involves the gestural modality and pointing in particular, may therefore constitute an important stage in the development of the ability to understand, predict, and manipulate the behaviour of others, in addition to the role played by earliest social experiences such as infant attachment security (e.g. Laranjo, Bernier, Meins, \& Carlson, 2010). 
However, the question of the relationships between declarative pointing and ToM abilities deserves further investigation. Declarative pointing actually includes declarative expressive and declarative informative pointing (Tomasello, Carpenter, \& Liszkowski, 2007): the former is produced to express and share some interest in a referent with a communicative partner, while the latter is used to give the partner helpful information about a referent. They are produced in different contexts and involve different motivations, which raises new questions as for the relationship between gestural communication and ToM abilities, especially as informative pointing has been reported to present specific behavioural characteristics. For example, toddlers alternate their gaze more frequently between the adult and the object pointed to in informative situations than in expressive situations (Cochet \&Vauclair, 2010b). Informative pointing has also been argued to develop jointly with cooperation abilities (e.g. Liszkowski, Carpenter, \& Tomasello, 2008), as it requires children's willingness to inform their partner. Meng and Hashiya (2014) have argued that infants' informative pointing may reflect their understanding of the adult's attentional and knowledge states: they designed an experimental situation in which 13-to 18-month-olds were presented with two objects, including one that had previously been the focus of shared attention between the infant and the experimenter (and infants were equally familiar with both the objects). Results have shown that infants pointed more frequently towards the object that was new to the experimenter than towards the familiar object.

In addition to pointing behaviour, instrumental helping has been reported in 18-month-old infants in situations where the adult has trouble achieving a specific goal, for example opening the door of a cabinet or grasping an out-of-reach object (Warneken \& Tomasello, 2006). Infants helped the adult by performing the target behaviour, in the great majority of cases before the latter looked at the infants or verbalized his problem, which has been regarded as evidence of both infants' understanding of other's intentions and of their altruistic motivation to help.

Nevertheless, clear-cut interpretations about the actual motivation and cognitive skills associated with such behaviours are difficult in prelinguistic or just-linguistic infants: the latter may point or perform the target action for reasons other than informing or helping the adult. Moreover, informative pointing might involve an implicit understanding of adults' behaviour rather than ToM skills per se, based in early stages on infants' abilities to observe and recognize human faces and motion patterns (Ruffman, 2014). In older children, the use of standard test batteries (e.g. Sally-Anne test, Wimmer \& Perner, 1983) relying on verbal explanations can help clarifying this issue, but so far, no studies have directly tested the existence of a relationship between ToM and the production of declarative pointing, by differentiating expressive from informative pointing.

In the present study, we thus combined the use of a standard ToM test with a declarative pointing task, in continuity with previous studies conducted in 
infants (e.g. Lizkowski et al., 2008) in order to investigate to what extent the two abilities are related in preschoolers. Focusing on 3 to 4-year-olds allowed us to significantly reduce the risk of uncertainty as to children's intentions and understanding of communicative situations. ToM abilities were also assessed with a parental questionnaire. Our main hypothesis was that the production of declarative informative pointing would be more closely related to ToM abilities than declarative expressive pointing.

\section{Method}

\section{Participants}

Thirty children (17 girls) aged between 37 months and 48 months $(M=42.6$ months; $S D=3.5)$ participated in the study. They were all raised by upper-middle-class French-speaking families and recruited in a preschool in PACA region, South-East France. Parents gave their written informed consent before inclusion in the study.

\section{Material and measures}

ToM abilities were first assessed with the Scaling of Theory of Mind Tasks (STM, Wellman \& Liu, 2004). Children were asked five questions involving characters of different stories, which aimed at evaluating (in the following order) their understanding of diverse desires (i.e. understanding that two people - the child vs. someone else - have different desires about the same object), diverse beliefs (i.e. understanding that two people - the child vs. someone else - have different beliefs about the same object), knowledge-access (i.e. understanding the knowledge of another person who does not see what is in a box), false belief (i.e. understanding another person's false belief about what is in a box when the child knows what it is in the box), and hidden emotion (i.e. understanding that a person can feel something but display a different emotion). For each story, the experimenter also asked children control questions to check for comprehension and memory (Wellman \& Liu, 2004). Children obtained one point for each correct answer, leading to a maximum of five points for the scale. Given the consistent developmental progression reported in several studies (e.g. understanding of desires precedes understanding of beliefs, see Wellman \& Liu, 2004), the tasks ended when children gave a wrong response or did not respond at all.

Second, we used a parental questionnaire that has been validated in a French population in order to complete the measures of ToM obtained with the STM tasks (EASE: Comte-Gervais, Giron, Soares-Boucaud, \& Poussin, 2008; see also Hughes, Soares-Boucaud, Hochman, \& Frith, 1997). This questionnaire is divided into two sub-scales: 25 questions assess the ability to represent others' mental states, including attention, motivation, intention, knowledge and emotional 
states (e.g. 'Is your child able to cheat in order to win a game whose rules he/ she understands?') and 25 questions focus on children's general capacities of social adaptation that do not require ToM abilities (e.g. 'does your child spontaneously use words like please, thank you, etc.?'). Parents were asked to indicate for each item whether their child frequently, occasionally, or never showed the corresponding behaviours, yielding a score of 2, 1, and 0 point, respectively. We thus established two scores for each sub-scale (EASE-ToM and EASE-NoToM), each varying between 0 and 50 .

For the pointing tasks, different toys and objects were used (e.g. a wooden puzzle, modeling clay of different colors, Russian dolls, plastic pearls, 'Mr. Potato' head toy), as well as a computer on which were shown some clips from children's cartoons (see the following section). Pointing was defined as an arm and hand movement, involving either index finger extensions or whole-hand gestures, used to intentionally direct the attention of a communicative partner towards a specific referent (here, an object or a picture). The definition and the tasks used were based on previous studies (Cochet \& Vauclair, 2010a, 2010b).

\section{Procedure}

Experiments took place during school time, over a 10-day period. The experimenter (CR) first spent one day in the classroom so that children start familiarizing with her. The EASE questionnaires were collected from the parents before the experiments, then three tasks were proposed to the children: the Scaling of Theory of Mind Task, a declarative expressive pointing task (5 trials) and a declarative informative pointing task ( 5 trials). This order of presentation facilitated the interactions with the experimenter, and was therefore the same for all the children. The experimenter and the child were seated at a table, opposite each other. All sessions were videotaped.

\section{Scaling of theory of mind tasks}

Several pictures were used to illustrate the five different stories, based on the study by Wellman and Liu (2004). The experimenter made sure that the children were attentive to the pictures and asked them if they had understood the story before asking the questions to assess ToM abilities. Stories were told a second time if necessary.

\section{Declarative expressive pointing task}

The experimenter initiated interactions with the child and after a few minutes, she discreetly used a remote control to start a short and soundless video clip (10 s) on a screen behind her. The child thus saw the clip appearing in front of him/her, unbeknown to the experimenter. If the child pointed towards the screen, the experimenter waited for the video clip to stop before turning back (a small mirror was used to control that the screen was black again), so that 
children remained willing to point in the following trials ( 5 in total). If the child did not produce any pointing, the experimenter moved on to the next task.

\section{Declarative informative pointing task}

While the experimenter and the child were playing with toys and objects that were composed of several elements, the experimenter pretended she could not find one of these elements (e.g. one of the Russian dolls, modeling clay of a specific color, etc.), which was actually on the table, visible by the child but out of his/her reach. She then said that they could not continue to play and started searching for the object, without asking the child about it. If the child pointed, the experimenter retrieved the object and thanked the child for his/her help. If the child did not produce any pointing within $10 \mathrm{~s}$, the experimenter directly asked 'where is the missing doll?', or an equivalent question, and waited for the child's reaction for a further $10 \mathrm{~s}$ before moving on to the next trial (5 in total) or ending the task. Pointing gestures produced after the prompt were also included in the data.

\section{Reliability}

Two experimenters separately coded all the video recordings at the end of the experiments. Kappa coefficients for the number of declarative expressive pointing, the number of declarative informative pointing, and scores to the Scaling of theory of mind (STM) task were respectively $1,0.71$ and 0.92 .

\section{Results}

Some of the following analyses were performed on a reduced sample of 27 children, given that three children did not produce any declarative expressive pointing (in the five trials, these children only provided verbal information to the experimenter, which was not coded in the present study). First, as age range of our sample varied between 37 and 48 months, we calculated Pearson correlation coefficients between age and the different dependent variables to test for a potential developmental effect. None of the correlations were significant, so we did not include age as a variable in our analyses. Similarly, $t$-tests performed on the different measures did not reveal any effect of children's gender, so boys and girls were regarded as a single sample.

\section{Descriptive results}

Scores obtained to the EASE questionnaire (sub-scales EASE-ToM and EASENoToM) varied respectively between 22 and $48(M=33, S D=6.6, N=30)$, and between 25 and $47(M=40, S D=5.9, N=30)$. Scores obtained to the STM task varied between 1 and $4(M=2.9, S D=0.8, N=30)$. Mean numbers of pointing gestures produced were $4.2(S D=0.9, N=27)$ in the declarative expressive task, 
Table 1. Pearson correlation coefficients between scores obtained to the EASE scale (ToM and NoToM sub-scales), the STM task and the declarative expressive (DEP) and declarative informative (DIP) pointing tasks.

\begin{tabular}{lccccc}
\hline & EASE - ToM & EASE - NoToM & STM task & DEP task & DIP task \\
\hline EASE - ToM & 1 & & & & \\
EASE - NoToM & $0.618^{* *}$ & 1 & & & \\
STM task & $0.479^{*}$ & 0.25 & 1 & & \\
DEP task & -0.078 & -0.029 & -0.11 & 1 & \\
DIP task & 0.314 & 0.021 & $0.405^{*}$ & -0.37 & 1 \\
\hline
\end{tabular}

${ }^{*} p<.05 ;{ }^{* *} p<.01$.

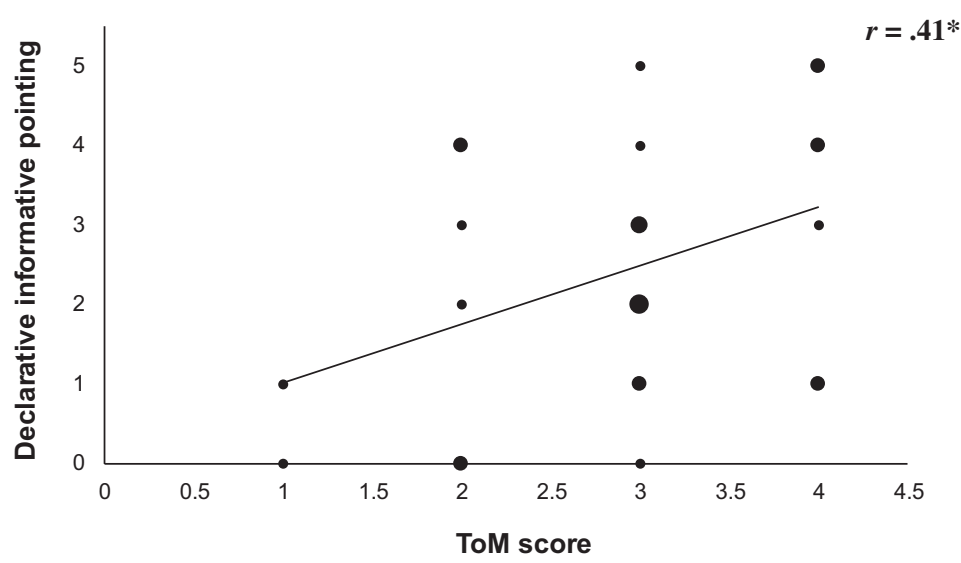

Figure 1. Relation between the number of declarative informative pointing produced and ToM abilities assessed with the STM task. The size of the points reflects the number of participants, varying between 1 and 4 depending on the scores. ${ }^{*} p<.05$.

and $2.4(S D=1.6, N=27)$ in the declarative informative task. When all trials were successful in the pointing tasks, children obtained a score of 5: this was the case for 14 children in the expressive task and 3 children in the informative task. In total, children produced 70 informative pointing gestures and 113 expressive pointing gestures.

\section{Correlation results}

We calculated correlation coefficients between the different variables of the study (see Table 1). Scores obtained to the two sub-scales of the EASE questionnaire (ToM and NO-ToM scores) were positively correlated, and scores in the ToM sub-scale were positively correlated to the scores obtained in the STM task. STM scores were also significantly correlated to the number of informative pointing produced (see Figure 1). 


\section{Discussion}

The objective of the present study was to determine to what extent the production of declarative pointing is related to ToM abilities in children between 3 and 4 years of age. First, our results have shown a significant correlation between ToM score on the STM task and the number of declarative informative pointing produced by children, whereas there was no correlation between STM score and the number of declarative expressive pointing. Both expressive and informative pointing appear in the child's gestural repertoire from 1 year of age (e.g. Liszkowski, 2005), and both have been argued to involve some understanding of the partner's attentional and knowledge states (Cochet \& Vauclair, 2010b; Meng \& Hashiya, 2014). But only the production of informative pointing may be considered as a form of pro-social behaviour, requiring cooperation abilities (Liszkowski et al., 2008), which indeed develop significantly over toddlerhood and childhood (Bar-Tal, Raviv, \& Goldberg, 1982; Svetlova, Nichols, \& Brownell, 2010) in relation to cognitive advances in social understanding (e.g. De Leon, del Mundo, Moneva, \& Navarrete, 2014). By contrast, the child's eagerness to share attention on a target of interest with a communicative partner may constitute the only prerequisite for the production of expressive pointing, even though the attentional states of the partner does influence some characteristics of the gestures (e.g. gaze or accompanying vocalizations, Legerstee \& Barillas, 2003). A difference in motivation between expressive and informative pointing - and potentially but not necessarily a difference in cognition - may thus explain our results. Besides, the greater frequency of expressive pointing compared to informative pointing may be explained by interrelated effects of both motivation and socio-cognitive factors: (1) children may be more motivated to share interest with a partner in expressive situations because the context is more obvious and immediate than in informative situations; (2) informative pointing may require more demanding social understanding than expressive pointing.

However, the correlation between ToM abilities and declarative informative pointing explained a small percentage of the variance $\left(R^{2}=.16\right)$ and our results do not address the question of causation: children who used more informative pointing gestures than others in the experimental task also had higher level of theory-of-mind, but this does not indicate that informative pointing is a precursor of ToM. Positive, although moderate, correlations have previously been reported between cooperation behaviour and ToM abilities in adults (Paál \& Bereczkei, 2007), as well as in children between 5 and 7 years of age (Caputi, Lecce, Pagnin, \& Banerjee, 2012), which suggests that the association between declarative informative pointing and ToM observed in the present study could be mediated by the development of cooperation abilities. Nonetheless, in children followed from 3 to 4 years of age, the relationship between early ToM and measures of prosocial behaviour such as cooperation was not found to be significant (Ruffman, Slade, Devitt, \& Crowe, 2006). Moreover, the correlation 
between informative pointing and ToM might actually reflect the relationships between each of these variables and language development, although there is no evidence in preschoolers that informative pointing is more closely associated with language than is expressive pointing.

Additional measures, involving in particular cooperation tasks and language assessment, but also elements of personality tests, will therefore be necessary in future studies to help (1) provide a larger picture of the relationships between children's developing socio-cognitive abilities, and (2) identify the mechanisms that mediate the relationships between informative pointing and ToM abilities. Analysing children's general language level and the characteristics of the verbalisations accompanying their pointing gestures (e.g. semantic, syntactic and prosodic properties) may allow us to describe triadic associations between declarative informative gestures, language and ToM abilities (e.g. Milligan et al., 2007). It would also feed the current debate about the importance of the verbal modality in ToM assessment: some ToM tasks, or some task items, rely indeed more than others on linguistic abilities, which might have led to an underestimation of ToM abilities in preschoolers (e.g. Norimatsu, Blin, Hashiya, Sorsana, \& Kobayashi, 2014).

Measuring the quantity and quality of support and stimulation available in children's environment would also be useful, even though these variables are difficult to operationalize. Indeed, nonverbal behaviours (i.e. pointing gestures but also other gestures and gaze behaviour such as gaze following) and the ability to understand and anticipate others' mental states may co-develop through dynamic joint attention frames that require both non-verbal and verbal stimulations from parents (e.g. Matthews, Behne, Lieven, \& Tomasello, 2012; Ruffman, 2014). However, data obtained by the parental questionnaire in the present study did not yield significant results: no correlation was found between scores at the EASE-ToM scale and the production of declarative pointing, contrary to direct measures of ToM with the STM task (although it may be important to note that, even if it did not reach significance, the correlation coefficient between the number of informative pointing and the score on the EASE questionnaire was higher for the ToM sub-scale than for the no-ToM one, for which it was almost null). This pattern of results might question the use of indirect methods to measure ToM abilities, but ToM scores obtained with the EASE scale were significantly correlated to those obtained with the STM task, reflecting some validity of the parental questionnaire. Moreover, our results have shown a significant correlation between the two sub-scales of the EASE questionnaire, indicating a strong association between ToM abilities and other abilities of social adaptation that do not require ToM. One way of improving the precision of this questionnaire would be to conduct semi-structured interviews (Comte-Gervais et al., 2008). In the present study, we collected the questionnaires without having the possibility of discussing the questions with the parents, which may have affected the accuracy of their answers, in addition to the risk of over- or underestimation 
of children's abilities, which constitutes a recurrent issue with indirect and selfreport measures. It may also be relevant to ask other adults for their opinion: teachers in particular are likely to provide rich information about interactions between children and manifestations of social understanding.

Other limitations of the present study also have to be considered: first, all children completed the informative pointing task after the ToM task and the expressive pointing task, as we expected this order of presentation to make children more willing to inform the adult. Even if the pointing tasks were included in play interactions with the experimenter, and did not last more than five minutes each, we cannot exclude the possibility that children lost interest and became less attentive over time and therefore produced less gestures in the informative task. Second, in the present study, approximately half of the children produced a gesture in all trials of the expressive pointing task, while they were only 3 to do so in the informative pointing task. It may therefore be useful to increase the number of trials and/or the complexity of the pointing tasks to reduce the risk of ceiling effects, while maintaining children's attention and motivation.

Given that the acquisition of ToM abilities in the course of development is usually regarded as a major achievement of the first years of life, our results may have some implications for developmental psychologists, teachers and parents. The present study provides direct evidence that the production of informative pointing is related to ToM abilities, and the latter plays a key role in social interactions, especially in school context by helping children establish and maintain social relationships with peers (e.g. Caputi et al., 2012; Fink, Begeer, Hunt, \& De Rosnay, 2014). The use of a training methodology, showing that it is possible to promote children's understanding of others' attentional and knowledge states (e.g. Lecce, Bianco, Demicheli, \& Cavallini, 2014), could therefore include informative pointing tasks, as this communicative behaviour seems to be a good nonverbal measure for ToM skills. Investigations of other factors that may contribute to preschoolers' developing ToM, starting with language development and social stimulation from environment, will shed further light on how we become able to take someone else's perspective and understand that people's behaviour is motivated by what goes on in their minds (e.g. Liszkowski, 2013), thus allowing children to interact with others appropriately and allowing adults to cooperate more willingly with communicative partners (Paál \& Bereczkei, 2007).

\section{Acknowledgements}

The authors would like to thank teachers of the preschools for their support and assistance, as well as the parents and their children for their participation.

\section{Disclosure statement}

No potential conflict of interest was reported by the authors. 


\section{References}

Asada, K., \& Itakura, S. (2012). Social phenotypes of autism spectrum disorders and Williams syndrome: Similarities and differences. Frontiers in Psychology, 3, 1-9.

Bar-Tal, D., Raviv, A., \& Goldberg, M. (1982). Helping behaviour among pre-school children: An observational study. Child Development, 53, 396-402.

Behne, T., Carpenter, M., \& Tomasello, M. (2014). Young children create iconic gestures to inform others. Developmental Psychology, 50, 2049-2060.

Camaioni, L., Perucchini, P., Bellagamba, F., \& Colonnesi, C. (2004). The role of declarative pointing in developing a theory of mind. Infancy, 5, 291-308.

Camaioni, L., Perucchini, P., Muratori, F., Parrini, B., \& Cesari, A. (2003). The communicative use of pointing in autism: Developmental profile and factors related to change. European Psychiatry, 18, 6-12.

Caputi, M., Lecce, S., Pagnin, A., \& Banerjee, R. (2012). Longitudinal effects of theory of mind on later peer relations: The role of prosocial behaviour. Developmental Psychology, 48, 257-270.

Charman, T., Baron-Cohen, S., Swettenham, J., Baird, G., Cox, A., \& Drew, A. (2001). Testing joint attention, imitation, and play as infancy precursors to language and theory of mind. Cognitive Development, 4, 481-498.

Cochet, H., Jover, M., \& Vauclair, J. (2011). Hand preference for pointing gestures and bimanual manipulation around the vocabulary spurt period. Journal of Experimental Child Psychology, 110, 393-407.

Cochet, H., \& Vauclair, J. (2010a). Features of spontaneous pointing gestures in toddlers. Gesture, 10, 86-107.

Cochet, H., \& Vauclair, J. (2010b). Pointing gestures produced by toddlers from 15 to 30 months: Different functions, hand shapes and laterality patterns. Infant Behaviour and Development, 33, 432-442.

Colonnesi, C., Rieffe, C., Koops, W., \& Perucchini, P. (2008). The pointing gesture and the intention understanding as precursors to a theory of mind. British Journal of Developmental Psychology, 26, 561-577.

Colonnesi, C., Stams, G., Koster, I., \& Noom, M. J. (2010). The relation between pointing and language development: A meta-analysis. Developmental Review, 30, 352-366.

Comte-Gervais, I., Giron, A., Soares-Boucaud, I., \& Poussin, G. (2008). Évaluation de l'intelligence sociale chez l'enfant [Assessment of social intelligence in children]. L'information Psychiatrique, 84, 667-673.

De Leon, M. P. E., del Mundo, M. D. S., Moneva, M. L. V., \& Navarrete, A. M. L. (2014). Manifestations of helping behaviour among preschool children in a laboratory school in the Philippines. Asia-Pacific Journal of Research in Early Childhood Education, 8, 1-20.

Fink, E., Begeer, S., Hunt, C., \& De Rosnay, M. (2014). False-belief understanding and social preference over the first two years of school: A longitudinal study. Child Development, 85, 2389-2403.

Hughes, C., Soares-Boucaud, I., Hochman, J., \& Frith, U. (1997). Social behaviour in pervasive developmental disorders: Effects of informant, group and "theory of mind". European Child and Adolescent Psychiatry, 6, 191-198.

Knudsen, B., \& Liszkowski, U. (2012). 18-Month-olds predict specific action mistakes through attribution of false belief, not ignorance, and intervene accordingly. Infancy, $17,672-691$.

Kristen, S., Sodian, B., Thoermer, C., \& Perst, H. (2011). Infants'joint attention skills predict toddlers' emerging mental state language. Developmental Psychology, 47, 1207-1219. 
Laranjo, J., Bernier, A., Meins, E., \& Carlson, S. M. (2010). Early manifestations of children's theory of mind: The roles of maternal mind-mindedness and infant security of attachment. Infancy, 15, 300-323.

Lecce, S., Bianco, F., Demicheli, P., \& Cavallini, E. (2014). Training preschoolers on first-order false belief understanding: Transfer on advanced ToM skills and metamemory. Child Development, 85, 2018-2404.

Legerstee, M., \& Barillas, Y. (2003). Sharing attention and pointing to objects at 12 months: Is the intentional stance implied? Cognitive Development, 18, 91-110.

Liszkowski, U. (2005). Human twelve-month-olds point cooperatively to share interest with and helpfully provide information for a communicative partner. Gesture, 5, 135154.

Liszkowski, U. (2008). Before L1: A differentiated perspective on infant gestures. Gesture, 8, 180-196.

Liszkowski, U. (2013). Using theory of mind. Child Development Perspectives, 7, 104-109.

Liszkowski, U., Carpenter, M., \& Tomasello, M. (2008). Twelve-month-olds communicate helpfully and appropriately for knowledgeable and ignorant partners. Cognition, 108, 732-739.

Matthews, D., Behne, T., Lieven, E., \& Tomasello, M. (2012). Origins of the human pointing gesture: A training study. Developmental Science, 15, 817-829.

Meltzoff, A. N. (1995). Understanding the intentions of others: Re-enactment of intended acts by 18-month-old children. Developmental Psychology, 31, 838-850.

Meng, X., \& Hashiya, K. (2014). Pointing behaviour in infants reflects the communication partner's attentional and knowledge states: A possible case of spontaneous informing. PLOS ONE, 9, e107579. http://dx.doi.org/10.1371/journal.pone.0107579

Mervis, C. B., \& John, A. E. (2010). Cognitive and behavioral characteristics of children with Williams syndrome: Implications for intervention approaches. American Journal of Medical Genetics, 154, 229-248.

Mervis, C. B., \& Klein-Tasman, B. (2000). Williams syndrome: Cognition, personality, and adaptive behavior. Mental Retardation Developmental Disabilities Research Reviews, 6, 148-158.

Milligan, K., Astington, J., \& Dack, L. A. (2007). Language and theory of mind: Metaanalysis of the relation between language ability and false-belief understanding. Child Development, 78, 622-646.

Mundy, P., \& Newell, L. (2007). Attention, joint attention, and social cognition. Current Directions in Psychological Science, 16, 269-274.

Norimatsu, H., Blin, R., Hashiya, K., Sorsana, C., \& Kobayashi, H. (2014). Understanding of others' knowledge in French and Japanese children: A comparative study with a disambiguation task on 16-38-month-olds. Infant Behaviour and Development, 37, 632-643.

Onishi, K. H., \& Baillargeon, R. (2005). Do 15-month-old infants understand false beliefs? Science, 308, 255-258.

Paál, T., \& Bereczkei, T. (2007). Adult theory of mind, cooperation, Machiavellianism: The effect of mindreading on social relations. Personality and Individual Differences, 43, 541-551.

Porter, M. A., Coltheart, M., \& Langdon, R. (2008). Theory of mind in Williams syndrome assessed using a nonverbal task. Journal of Autism and Developmental Disorders, 38, 806-814.

Repacholi, B., \& Gopnik, A. (1997). Early reasoning about desires: Evidence from 14- and 18-month-old. Developmental Psychology, 33, 12-21.

Ruffman, T. (2014). To belief or not belief: Children's theory of mind. Developmental Review, 34, 265-293. 
Ruffman, T., Slade, L., Devitt, K., \& Crowe, E. (2006). What mothers say and what they do: The relation between parenting, theory of mind, language and conflict/cooperation. British Journal of Developmental Psychology, 24, 105-124.

Southgate, V., Senju, A., \& Csibra, G. (2007). Action anticipation through attribution of false belief in two-year-olds. Psychological Science, 18, 587-592.

Stefanini, S., Bello, A., Iverson, J. M., Caselli, M. C., \& Volterra, V. (2009). Co-speech gestures in a naming task: Developmental data. Language and Cognitive Processes, 24, 168-189.

Svetlova, M., Nichols, S. R., \& Brownell, C. A. (2010). Toddler's prosocial behaviour: From instrumental to altruistic helping. Child Development, 81, 1814-1827.

Tomasello, M., Carpenter, M., \& Liszkowski, U. (2007). A new look at infant pointing. Child Development, 78, 705-722.

Warneken, F., \& Tomasello, M. (2006). Altruistic helping in human infants and young chimpanzees. Science, 311, 1301-1303.

Wellman, H., \& Liu, D. (2004). Scaling of theory-of-mind tasks. Child Development, 75, 523-541.

Wimmer, H., \& Perner, J. (1983). Beliefs about beliefs: Representing and constraining function of wrong beliefs in young children's understanding of deception. Cognition, 13, 103-128.

Yirmiya, N., Erel, O., Shaked, M., \& Solomonica-Levi, D. (1998). Meta-analyses comparing theory of mind abilities of individuals with autism, individuals with mental retardation, and normally developing individuals. Psychological Bulletin, 124, 283-307. 